\title{
Cloze test pocket worksheet as aid to mastery of science concepts
}

\author{
Adelita M. Gomba \\ Department of Education, Silanga National High School, Catbalogan City, Philippines
}

\begin{tabular}{l}
\hline \hline Article Info \\
\hline Article history: \\
Received Sep 29, 2018 \\
Revised Oct 20, 2018 \\
Accepted Jan 19, 2019 \\
\hline
\end{tabular}

\section{Keywords:}

Aid

Cloze test

Mastery

Pocket worksheet

Science concepts

\begin{abstract}
This study used a Two Groups, Random Selection Experimental Design to improved academic performance of Grade 9 learners of Silanga National High School Catbalogan City using Cloze Test Pocket Worksheet in Science. Its purpose was to seek answers to the following questions: (1) What is the pretest mean scores between the control and experimental group? (2) What is the posttest mean scores of the control and experimental group? (3) What is the mean gain scores of the selected experimental group before and after the conduct of the study? Based on the result, the following findings were formulated; (1) The pretest mean scores of the subjects using Cloze Test Pocket Woksheet and the pretest mean scores of those who did not used do not differ significantly. (2) The post-test means scores of subjects who were were using Cloze Test Pocket Woksheet and the posttest mean scores of the subjects who were not using Cloze Test Pocket Woksheet differ significantly. (3) There is a significant difference between the mean gain scores of the two groups of samples - experimental and control groups. The experimental group who used Cloze Test Pocket Woksheet performed significantly higher than the control group who were not using the Cloze Test Pocket Woksheet. Based on the findings cited, it is concluded that the developed material in reviewing Science can improve learners' mastery of the concepts. Though the results of this study showed that learning took place in both groups, the subjects who were assessed by Cloze Test Pocket Worksheet performed significantly better than the subjects who did not use the material.
\end{abstract}

Copyright $(2019$ Institute of Advanced Engineering and Science. All rights reserved.

\section{Corresponding Author:}

Adelita M. Gomba,

Department of Education,

Silanga National High School,

Silanga, Catbalogan City, Philippines 6700.

Email: adelleyson27@gmail.com

\section{INTRODUCTION}

Anyone around the world may experience to forget information under certain circumstances. This failure to remember has several reasons and many suggestions had been presented to avoid occurrence of more difficulties and overcome such problem. Consequently, the inability to recall something learned earlier may compromise the quality of education among students which hinders the attainment of standards in terms of content, performance and learning outcomes as aimed by the Department of Education through the implementation of $\mathrm{K}$ to 12 Curriculum.

Teachers however, though have busy schedules either inside or outside the classroom would not want all that were taught to students are forgotten as soon as it was learned. Moreover, saving time and increasing the likelihood of students to remember what were taught requires time for review and its effect is quite worthy.

Hoffman mentioned the Curve of Forgetting which shows how human remember or forget information learned or memorized. Basically, at the beginning of instruction, teacher assumes students know 
zero percent of what is going to be tackled [1]. At the end of the instruction each student will know 100 percent of what each learnerl believed important, however reality tells that brains discard the rest.

The core elements of mastery learning provide the foundation for other innovative models, including Response to Intervention. Students vary widely in learning rates, and all learn well when provided with the necessary time and appropriate learning conditions. If teachers could provide the time and more suitable conditions, Bloom cited in Guskey mentioned that nearly all students could reach a high level of learning [2]. Furthermore, typical group-based classrooms are observed that most teachers begin by dividing the concepts and skills that they want students to learn into smaller learning units. Following instruction on the unit, teachers administer an assessment to determine how well students have learned those concepts and skills. Based on the assessment results, students are sorted, ranked, and assigned grades. The assessment signifies to students the end of the unit and the end of the time they need to spend working on the unit material. It also represents their one and only chance to demonstrate what they have learned [3].

Based on several studies on how learners learn, educators have identified many techniques and strategies for students' retention of lessons taught. Pasha claimed that forgetting takes place as soon as we stop learning. Students' therefore need to recall immediately after learning and it must continue after intervals. Learning must be carried beyond the point where recall is just barely possible. Over learning, beyond the point of complete mastery, strengthens the impressions in the brain [4]. Block categorized mastery learning as an optimistic theory about teaching and learning. It is an effective set of individualized instructional practices that consistenltly help most students to learn excellently [5].

Presently, many Filipinos find Science a difficult subject to grasp and may lead to low grades and sometimes failures and dropping out which will clearly affect students' academic success and school's performance. Having poor ability to remember vocabulary, acquire basic ideas, and expressing clearly on science concepts are communication difficulties that hinder some learning in the subject. Students tend to forget the lesson a day after the discussion and lead to manifestation of less mastery of Science concepts taught. This suspected deficiency in the retention of concepts is the main problem of this study and further viewed its relationship to academic performance.

The researchers adopted the Cloze Test technique to address the mentioned problem above. The Cloze Test is a common empirical comprehension test. It works by replacing every nth word in the text with blanks [6]. In this case, the researcher developed a Cloze Test Pocket Worksheet on Science concepts to determine mastery of the lesson taught to selected Grade 9 learners' of Silanga National High School, Catbalogan City for the school year 2017-2018. The developed material enabled the learner to review at frequent intervals to prevent the decay of the learnt data or information.

Theoretical Background, this study is guided on Gestalt Principles of Closure which says that the brain sees things as a whole unit and will naturally and easily fill in missing elements [7]. On the other hand, a person will opt their past experiences or previous knowledge accompanied with critical thinking and reasoning skills to fill in the blanks when an information is missing. According to Shohamy as cited from Oller, who extensively researched the Cloze procedure, writes that it would seem that the perceiver's ability to fill in gaps in imperfect patterns may be related to the ability to construct the patterns [8]. This principle is in consonance with Brain plasticity that refers to the brain's ability to change and adapt as a result of experience by forming new connections [9].

Statement of the problem, this study was designed to improve the academic performance of Grade 9 learners using the Cloze Test Pocket Worksheet as review assessment. Specifically, it sought to answer the following questions:

a. What is the pretest mean scores between the control and experimental group?

b. What is the posttest mean scores of the control and experimental group?

c. What is the mean gain scores of the selected experimental group before and after the conduct of the study?

Review of related literature and studies, students attending elementary schools with fully implemented comprehensive guidance and counselling program shows significant increase in the academic achievement rather than those students enrolled in schools with non-comprehensive guidance and counselling program [10]. This investigation appears to support the notion that young children may benefit academically whether they are economically disadvantaged or not. This emphasize that any focused intervention may help increase academic performance of students like developed test material and implementation of clear assessments to identify mastery of concepts learned.

Todd as cited in Douglas stated that if reading passages are too difficult, learners can't activate their background knowledge and become clause dependent [11]. Therefore, cloze texts should be carefully constructed by choosing an applicable text for the student group to ensure a passage is of an appropriate level of difficulty for the learners being tested and that it contains culturally familiar content and this technique 
may be helpful for poor readers to improved comprehension [12-14]. Similarly, students can raise their scores on aptitude and achievement tests by taking practice forms of the tests [15]. If constant drill will be used to test mastery of concepts on the learners will create bigger connections on the neurons which will make learners study habits continuous.

Raymond used cloze procedure as reading strategies in her study entitled Cloze Procedure in the Teaching of Reading. She concluded that this strategy if given proper preparation by the teacher can be an effective teaching technique and can be used as reading strategy to build wide reading comprehension $[16,17]$.

In the same manner Kaminsky hypothesized that the task of filling deleted words in a written text is related to the way in which readers process language in reading. In addition, readers recall important concepts that may be significant or related to the statement given [18]. Use of cloze tests in their fixed-ratio deletion, exact-word scored format is recommended, with certain limiting considerations. In other words, well-designed cloze tests are capable of assessing language skills ranging from basic to advanced [19] can be used to measure a range of abilities [20].

Creating cloze test pocket worksheet to potential users bring several aids. Parents are encouraged when they see worksheets in their childrens bakpacks; they see such papers as indicators that their children are learning [21]. Other benefits include greater flexibility and interactivity, student focus, potential for follow-up, cost-effectiveness, and staff training [22]. Mortensen also documented in his study that the use of carefully designed worksheets may increase students' exposure to curriculum during museum visits [23] and to assess whether students completing a 'reflective' learning activity based on a structured worksheet really were reflecting [24]. In addition, blanks in worksheets are invitations for students to fill in gaps; they are opportunities for knowledge construction. Well-designed questions in worksheets can draw students' interest when paired with proper teaching methods [25]. Hence, Worksheet is one of the most important materials for achieving the goals of educational activities [26].

All these related studies used cloze technique in teaching reading and assessing comprehension. The present study used cloze test technique to increase students' retention in every lesson discussed in the classroom as a tool for assessing students' mastery of learning in Science subject.

Furthermore, the results of this investigation made beneficial to the students in terms of increase grade in Science and especially mastery of Science concepts. The Science teachers also will be able to find or identify varied teaching strategies and approaches, meaningful activities and appropriate assessments to be employed for the students making learning fun and enjoyable. Likewise, study like this will help school Administrators to implement programs and projects relevant in redirecting the present achieved level of performance of students in the subject.

\section{RESEARCH METHOD}

This study utilized the Two Groups, Random Selection Experimental Design which is illustrated below;

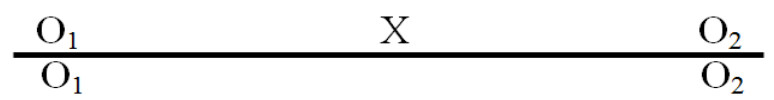

The "X" represents the treatment of the study, which is the Cloze Test Pocket Worksheet. The " $\mathrm{O}_{1}$ " denotes the pretest and the " $\mathrm{O}_{2}$ " denotes the posttest of the experimental and the control group. The experimental group underwent drill and review using the Cloze Test Pocket Worksheet.

The subject of this study were Sixty (60) Grade 9 learners of section Earth, Silanga National High School for the school year 2017-2018. Thirty (30) learners for the experimental group were randomly selected using fishbowl method and the remaining thirty (30) learners were considered as the control group. The observed group was drilled and reviewed using Cloze Test Pocket Worksheet.

This study utilized the following instruments: (1) Grade 9 Science Learners'Module, First Edition, 2014; (2) Teacher-made test, test which was used to measure the subjects' pretest and posttest achievement; and (3) Cloze Test Pocket Worksheet which was used daily as drill or review method of the previous lesson. Passages used in the Cloze Test Pocket worksheet were adopted from the Grade 9 Science Learners'Module.

To ensure the content validity of the test, a table of specification was constructed and the researcher prepared a fifty - item objective type of test following the revised Bloom's Taxonomy. The initial copy of the test was submitted and reviewed for correction to Science Department Chairman of the school. The test was given to students who already attended the class which was Grade 11 Senior High students of Silanga 
National High School. The result was analyzed using the test result analyzer. The final revision of the test questionnaire was based on the result of item analysis. The learners' used the learners' modules issued by the Department of Education. The Cloze Test Pocket Worksheets were prepared by the researcher and were subjected to face and content validity by fellow Science teachers in the school for material applicability.

The researcher who handled the class discussed on how the process of the study should be done starting from the pretest down to the posttest. Everyday, lesson was conducted by the researcher. Learned concepts for each lesson will be reviewed the following day before discussing new concepts. During Review as part of the lesson plan, selected experimental group stayed separately from half of the class and used the Cloze Test Pocket Worksheet which lasts only for ten minutes. Test participants were asked to read the modified/adopted text and fill in the blanks with the correct term as to the missing word. Each learner should work alone. The learner should get 75 percent correct words to pass the assessment. Synonyms and misspellings are allowed since the test is used to test comprehension and mastery of the concept. Two sets of tests were administered to the groups before and after the series of lessons agreed. The pretest was given before the experimentation began, and the posttest was administered after the instruction was conducted specifically during the periodical test. The study was conducted from June to August of school year 2017 2018. After gathering the data, it was treated statistically, analyzed, and interpreted. T - test for dependent samples was used to test whether the pretest and posttest mean scores significantly differ on the selected experimental group.

\section{RESULTS AND ANALYSIS}

This part presents the data gathered from the experimental and control groups using the Periodical test. The results are presented according to the statement of the specific questions that directed the study. Table 1 presents the pretest mean scores of the control and experimental groups with 1.33 mean difference with a $p$ value of 0.286 which is greater than the 0.05 level of significance. This result means that the difference is insignificant and entails that the two groups of respondents have comparatively the same standing at the start of the study. Further, it shows that learners interpret new concepts based on their past experiences which is limited due to varied concepts that are remembered. Low result of the pretest is quite normal for the respondents because they have slight knowledge about the new lesson.

Table 1. T-Test of the Difference in the Pretest Mean Scores Between the Control and the Experimental

\begin{tabular}{cccccccc} 
& \multicolumn{7}{c}{ Groups } \\
\hline Groups & $\mathrm{N}$ & Mean & SD & Mean Difference & t-test & $\mathrm{p}$ & Interpretation \\
\hline Control & 30 & 14.47 & 1.04 & 1.33 & 1.09 & 0.286 & Not significant \\
Experimental & 30 & 13.33 & & & & & \\
\hline
\end{tabular}

Table 2 demonstrates the posttest mean scores of the 30 and 30 respondents from the control and experimental groups with a mean difference of -3.43 and a p value of 0.000743 which is less than the 0.05 level of significance and gives a significant result. The computed $t$ value clearly suggests that the developed worksheet would help learners' performance improve. Result of the posttest of the observed group show that there is a significant change in the performance of the subjects. The brain never stops changing through learning, as theory of neuroplasticity suggests, if the brain is exposed and constantly working on a particular skill, the learner will be expert or will master the skill.

Table 2. T-Test of the Difference in the Posttest Mean Scores Between the Control and the Experimental Groups

\begin{tabular}{cccccccc}
\hline Groups & $\mathrm{N}$ & Mean & $\mathrm{SD}$ & Mean Difference & $\mathrm{t}$-test & $\mathrm{p}$ & Interpretation \\
\hline Control & 30 & 37.17 & 0.91 & -3.43 & -3.77 & 0.000743 & Significant \\
Experimental & 30 & 40.60 & & & & & \\
\hline
\end{tabular}

Table 3 shows the mean gain scores of both the control and experimental groups which obtained a mean gain of 4.57 setting a significant $\mathrm{p}$ value of 0 . 001. From the results above, it is implied that the use of Cloze Test Pocket Worksheet for drill and review is an effective method of reviewing concepts learnt and help improve the performance of learners because the subjects have the chance to have a constant interval of recalling the lesson hence prevent forgetfullness. This is supported by Gestalt Principles of Closure which says that the brain sees things as a whole unit and will naturally and easily fill in missing elements [6]. And 
using previous knowledge accompanied with critical thinking and reasoning skills to fill in the blanks when an information is missing.

Table 3. T-Test of the Mean Gain Scores Between the Control and Experimental Groups

\begin{tabular}{cccccccc}
\hline Groups & Pretest & Posttest & Mean Difference & Mean Gain & t-test & $p$ & Interpretation \\
\hline Control & 14.47 & 37.17 & 22.7 & 4.57 & 3.58 & 0.001 & Significant \\
Experimental & 13.33 & 40.60 & 27.27 & & & & \\
\hline
\end{tabular}

\section{CONCLUSION}

The pretest mean scores of the subjects using Cloze Test Pocket Woksheet and the pretest mean scores of those who did not used do not differ significantly. The post-test mean scores of subjects who were were using Cloze Test Pocket Woksheet and the posttest mean scores of the subjects who were not using Cloze Test Pocket Woksheet differ significantly. There is a significant difference between the mean gain scores of the two groups of samples - experimental and control groups. The experimental group who used Cloze Test Pocket Woksheet performed significantly higher than the control group who were not using the Cloze Test Pocket Woksheet.

From the results above, it is concluded that the use of Cloze Test Pocket Worksheet in teaching Science specifically reviewing lessons, is an effective approach. Effective in the sense that it helped the subjects of the study learn and master concepts taught. Further, this technique was deemed useful for the respondents in developing their individual learning study habits.

Mathematics teachers should determine students' prior knowledge in mathematics before starting the lesson to identify topics which have not learned. Teachers should utilize Cloze Test Pocket Worksheet to aid mastery in Science concepts. School administrators require teachers to use the developed worksheet in other Science subjects of Silanga National High School to test its effectiveness. Future researchers should conduct a true experimental study similar to this study to determine the effect of Cloze Test Pocket Worksheet on the academic performance of students in other learning areas to confirm its effectiveness.

\section{ACKNOWLEDGEMENTS}

I would like to thank Rhum O. Bernate, School Principal of Silanga National High School for allowing me to conduct my study. I am grateful also to the time of Ma. Linda Legarse, Ph. D. which was always open whenever I had a question about my research writing. I would also like to thank the experts, my fellow science teachers who were involved in the validation of the test questionnaire for this research project. Without their fervent participation and input, the test dry run could not have been successfully conducted.

\section{REFERENCES}

[1] Hoffman, and Sandy, "Why students forget What they' ve Learned and How to Increase Learning Retention," Reading Horizons, Oct, 2014.

[2] Guskey TR, "Lessons of mastery learning," Educational leadership, vol. 68, no. 2, pp. 52, 2010.

[3] Guskey, and Thomas R, "Mastery-Based Educational Approach," Dec, 2009.

[4] Pasha, and Saba, "FORGETTING - Concept, Types, Causes, Educational Implications," Jul, 2015.

[5] Block JH, "Promoting excellence through mastery learning," Theory into practice. vol 19, no. 1, pp. 66-74, 1980.

[6] Nielsen J, "Cloze test for reading comprehension," vol 15, Oct 2017.

[7] Bradley, and Steven, "Design Principles: Visual perception and the principles of gestalt," Mar 2014.

[8] Shohamy EG, "The Cloze Procedure and Its Applicability for Testing Hebrew as a Foreign Language," 1981.

[9] Michelon P, "Brain plasticity: How learning changes your brain," vol 24, 2009. Retrieved August. 2016.

[10] Sink CA, and Stroh HR, "Raising achievement test scores of early elementary school students through comprehensive school counseling programs," Professional school counselling, vol. 6, no. 5, pp. 350-64, Jun 2003.

[11] Todd L, "Using cloze tests to assess the reading needs of EAL learners."

[12] Mcgee LM, "Effects of the Cloze Procedure on Good and Poor Readers' Comprehension," Journal of Reading Behavior. vol 13, no. 2, pp. 145-56, Jun 1981.

[13] Sasaki M, "Effects of cultural schemata on students' test-taking processes for cloze tests: a multiple data source approach," Language Testing, vol 17, no. 1, pp. 85-114, Jan 2000.

[14] Brown JD, Yamashiro AD, and Ogane E, "The emperor's new cloze: strategies for revising cloze tests," A focus on language test development: Expanding the language proficiency construct across a variety of tests, pp. 143-61, 2001.

[15] Kulik JA, Kulik CL, and Bangert RL, "Effects of practice on aptitude and achievement test scores," American Educational Research Journal, vol .21, no. 2, pp. 435-47, 1984 
[16] Raymond PM, "Close procedure in the teaching of reading," TESL Canada journal, vol. 6, no. 1, pp. 91-7, Oct 1988.

[17] Taylor WL, "Cloze procedure: A new tool for measuring readability," Journalism Bulletin. vol 30, no. 4, pp.415-33, Sep 1953.

[18] Kaminsky S, "Taking a closer look at the cloze procedure," Literacy Research and Instruction. vol 19, no. 1, pp. 12-8, Oct 1979;

[19] Fotos SS. "The cloze test as an integrative measure of EFL proficiency: A substitute for essays on college entrance examinations?," Language learning, vol 41, no. 3, pp. 313-36, Sep 1991.

[20] Bachman LF, "Performance on cloze tests with fixed-ratio and rational deletions," Tesol Quarterly, vol 19, no. 3, pp. 535-56, Sep 1985.

[21] Ransom M, and Manning M, "Teaching Strategies: Worksheets, worksheets, worksheets," Childhood Education, vol 89, no. 3, pp. 188-901, May 2013.

[22] MacMillan D, "Web-based worksheets in the classroom," Journal of library \& information services in distance learning, vol 1, no. 2:43-51, 6 Jul, 2004

[23] Mortensen MF and Smart K, "Free-choice worksheets increase students' exposure to curriculum during museum visits," Journal of Research in Science Teaching, vol 44, no. 9, pp. 1389-414, Nov 2007.

[24] Pee B, Woodman T, Fry H, and Davenport ES, "Appraising and assessing reflection in students' writing on a structured worksheet," Medical education, vol 36, no. 6, pp. 575-85, Jun 2002.

[25] Lee CD, "Worksheet usage, reading achievement, classes' lack of readiness, and science achievement: A crosscountry comparison," International Journal of Education in Mathematics, Science and Technology, vol 2, no. 2,2014

[26] Kaymakci S, "A Review of studies on worksheets in Turkey," Online Submission, 2012.

\section{BIOGRAPHIES OF AUTHORS}

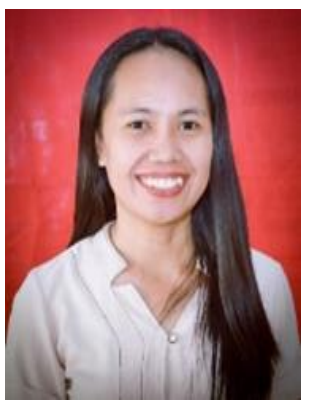

Adelita M. Gomba teaches Science, Mathematics, and Computer subjects at Silanga National High School, Catbalogan City. I graduated my Masters in Education major in Chemistry at Samar State University last 2013.My current research interests include using Cloze Test Modules to increase independent readers. I am an ICT Coordinator and certified Natural farmer.

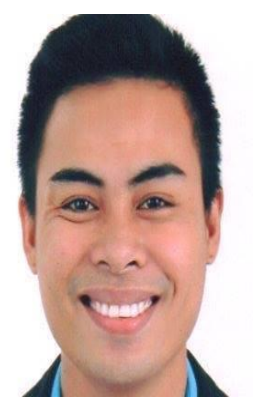

Perlito S. Domingo currently teaches Social Science in the Social Science Department at Silanga National High School, Catbalogan City. He graduated Bachelor of Secondary Education major in Social Studies at Samar State University, where he also curently taking his Masters Degree. 